\title{
GARCH GAMMA
}

Robert F. Engle

Joshua V. Rosenberg

Working Paper No. 5128

\section{NATIONAL BUREAU OF ECONOMIC RESEARCH 1050 Massachusetts Avenue \\ Cambridge, MA 02138 \\ May 1995}

This paper is part of NBER's research program in Asset Pricing. Any opinions expressed are those of the authors and not those of the National Bureau of Economic Research.

() 1995 by Robert F. Engle and Joshua V. Rosenberg. All rights reserved. Short sections of text, not to exceed two paragraphs, may be quoted without explicit permission provided that full credit, including () notice, is given to the source. 


\title{
GARCH GAMMA
}

\begin{abstract}
This paper addresses the issue of hedging option positions when the underlying asset exhibits stochastic volatility. By parameterizing the volatility process as GARCH, and utilizing risk-neutral valuation, we estimate hedging parameters (delta and gamma) using Monte-Carlo simulation. We estimate hedging parameters for options on the Standard and Poor's 500 index, a bond futures index, a weighted foreign exchange rate index, and an oil futures index.

We find that Black-Scholes and GARCH deltas are similar for all the options considered, while GARCH gammas are significantly higher than BS gammas for all options. For near the money options, GARCH gamma hedge ratios are higher than BS hedge ratios when hedging a long term option with a short term option. Away from the money, GARCH gamma hedge ratios are lower than BS.
\end{abstract}

Robert F. Engle

Economics Department

University of California, San Diego

9500 Gilman Drive

La Jolla, CA 92093-0508

and NBER
Joshua V. Rosenberg

Economics Department

University of California, San Diego 9500 Gilman Drive

La Jolla, CA 92093-0508 


\section{Introduction}

Constructing a hedge for an options position involves minimizing exposure to factors that influence the option price. The primary risk factors for an option are changes in the price and volatility of the underlying asset. This paper explores the issue of hedging options when trading occurs in discrete time and volatility follows a stochastic process in which the magnitude of recent price changes provides information about future volatility. Transactions costs are assumed to be zero, interest rates are assumed constant over the life of the option, and dividends are assumed to be known.

Initially, consider the problem of hedging options under the Black and Scholes (1973) assumptions of continuous trading and constant volatility over the life of the option. In deriving their option pricing formula, Black and Scholes utilize the linear relationship between the change in the option price and the change in the underlying price over an infinitesimal unit of time. This means that a perfect dynamic hedge for an options position can be formed by selling short a given number (delta) shares of the underlying. If volatility is deterministic, but not constant, Merton (1973) shows that a perfect hedge can be formed if average volatility is used for the underlying asset's volatility.

Assuming that hedging occurs in discrete time complicates the hedging process. Boyle (1980) shows that if continuous trading is possible, but hedging occurs in discrete time, option and underlying price behavior are no longer perfectly correlated. The option price response to large underlying price changes is convex, so that a delta hedge is no longer riskless. The second derivative of the Black-Scholes formula with respect to the underlying price, gamma, measures this characteristic.

In this case, in addition to the underlying asset, hedging an option position requires a hedging instrument correlated with convexity. Possible candidates for additional 
hedging instruments are options on the same underlying asset with a different strike, or with a different maturity.

Relaxing the assumption of deterministic volatility presents additional challenges. Under stochastic volatility, the option price will respond to random changes in volatility as well as random changes in the underlying price. Thus, an option hedge requires a hedging instrument correlated with the random change in volatility. Again, the natural hedging instrument is an option on the same underlying with some other difference in contract specification.

It is now clear that hedging an options position in discrete time under stochastic volatility will require the underlying and at least one additional option. However, since the Black-Scholes assumptions have been relaxed, the problem of option pricing must be re-examined.

There has been a substantial literature concerning pricing options under stochastic volatility in continuous time. Johnson and Shanno (1987), Scott (1987), Wiggins (1987), and Hull and White (1987a) derive option pricing formulas when the underlying asset follows a diffusion with stochastic variance. Except for Wiggins, they all make assumptions in order to invoke risk-neutral pricing, and estimate option prices using Monte-Carlo techniques. More recently, Ball and Roma (1994), Stein and Stein (1991), and Heston (1993) find closed form solutions for option prices in continuous time for various stochastic volatility processes.

Option pricing in discrete time has received substantial attention as well. Rubinstein (1976) shows that the Black-Scholes formula can be derived in discrete time, with the standard BS assumptions, assuming that the underlying price and consumption are jointly lognormal. Brennan (1979), Lee, Rao, and Auchmuty (1981), and Stapleton and Subrahmanyam (1984) derive option pricing results in discrete time in a more general 
framework. Amin and Ng (1993) and Duan (1995) address the issue of option pricing in discrete time under stochastic volatility. Duan finds an equivalent martingale measure that can be used for risk-neutral pricing in the GARCH-in-mean model under certain restrictions on preferences and distributions. Amin and $\mathrm{Ng}$ derive an option pricing formula under systematic stochastic volatility.

As trading intervals shrink, we could view our discrete time problem as an approximation to continuous time, and invoke the assumptions given in previous papers for risk-neutral valuation in continuous time. Alternatively, we could apply the discrete time results under the assumption that there is no risk premium for volatility, and the preference and distribution restrictions given in Duan. In either case, we assume that if there is a leverage effect, it is small enough so that risk-neutral pricing is an acceptable approximation.

Since there is generally not a closed form solution to the option pricing problem under stochastic volatility, we use Monte-Carlo simulation to price options, and finite differences to estimate hedge ratios. Polynomial functions are fitted to estimated hedge ratios to give a closed form.

We select the GARCH-t components with leverage model developed by Engle and Lee (1993) as a particularly appealing representation of the volatility process. The GARCH components with leverage model nests the GARCH(1,1) and GARCH-t models developed by Bollerslev (1986,1987). It explicitly accounts for the relationship between the magnitude of recent price changes and volatility, incorporates relatively complex dynamics in mean reversion, and allows for an asymmetric effect of "bad news"on volatility. The leverage effect follows the model developed by Glosten, Jagannathan, and Runkle (1993). 
The GARCH hedging parameters we estimate differ from Black-Scholes hedging parameters, because GARCH parameters incorporate the interrelationship between underlying price changes, volatility, and the option price. For instance, Engle and Rosenberg (1994) show that for at-the-money options, GARCH gamma is weighted average of Black-Scholes gamma and vega. Under GARCH, a large price shock affects the option price through convexity and through an increase in volatility. In addition, GARCH delta incorporates the direct effect on the option price due to its direct correlation with the underlying, and the indirect effect of an increase in volatility that follows "bad news."

The paper is organized as follows. The second section discusses previous theoretical and empirical results concerning options hedging. The third section of the paper describes the methodology of our study. In the fourth section, we report and analyze the results from estimation of the GARCH volatility models for the Standard and Poor's 500 index, a bond futures index, a weighted foreign exchange index, and an oil futures index. In the fifth section, we present the GARCH estimated hedging parameters and discuss their implications for hedge portfolio formation. We summarize our results in section six.

\section{Option hedging tests}

The issue of hedging options positions has been previously examined in several contexts. Galai (1983) analyzes the returns from delta hedged positions for options on individual stocks traded on the CBOE. The Black-Scholes model, with volatility held constant, is found to be unable to explain the observed average option returns. This suggests that there may be missing factors that drive the option price, such as stochastic volatility.

Hull and White (1987b) consider the problem of hedging non-exchange traded foreign currency options with exchange traded options and the underlying currency. They derive a general model in continuous time with delta, gamma, and vega hedge 
parameters. In simulations and tests of hedging currency options on the Philadelphia Stock Exchange, they find that delta-gamma hedging works best under "fairly constant implied standard deviation" (p. 147) and short times to maturity, while delta-vega hedging works best in the opposite situation.

The primary problem with their empirical tests is pricing of the non-exchange traded options. They price these options by Black-Scholes evaluated at the implied standard deviation of the exchange traded option. Observed differences between quoted and Black-Scholes prices, especially for away-from-the-money options, make this a tenuous assumption. It is also unclear that the implied volatilities are substitutable between options with a different maturity and strike prices, since the implied volatilities may reflect option specific mispricing as well as volatility information. In addition, the simulations which agree with these empirical results rely on a volatility process that is independent of underlying prices.

Engle and Rosenberg (1994) test the effectiveness of GARCH gammas in hedging medium term at-the-money S\&P500 index options with short term at-the-money options. GARCH gammas differ from those in this study, because they are derived analytically from an approximate stochastic volatility option pricing formula, using a GARCH components model with no leverage. However, the analytic gammas are shown to be close to the Monte-Carlo simulated gammas for at-the-money options. This paper also models in and out-of-the-money hedge parameters, for which simulation is essential.

In Engle and Rosenberg (1994), delta-GARCH gamma hedges outperform BlackScholes delta hedges and delta-vega hedges derived from an autoregressive volatility model. But, delta-GARCH gamma hedges are less successful than Black-Scholes deltagamma hedges. On average, GARCH gamma hedge ratios are found to be too high over the sample period, possibly implying overreaction of short term options to volatility 
news. Mispricing is also suggested as a possible explanation for Black-Scholes deltagamma hedging success.

Problems with using option pricing formulas derived from arbitrage-based arguments are examined by Figlewski (1989). He finds evidence from simulations that transactions costs, market imperfections, and discrete rebalancing make it possible only to establish bounds, rather than uniquely determine an option price. In this case, options hedge ratios are not well defined. In addition, in a study of the 30 most actively traded individual stock options on the CBOE, Figlewski and Freund (1994) find evidence that gamma and theta risk are priced. This suggests that risk-neutral pricing may be an inadequate approximation for deriving hedge parameters.

Discretely rebalanced as opposed to continuously rebalanced hedges present additional complications. Robins and Schachter (1994) show that a Black-Scholes delta-hedge is not a variance minimizing hedge over a non-instantaneous time interval. Gilster (1990) shows that hedges rebalanced over a long period of time may exhibit systematic risk. Chen and Johnson (1985) as well as Wolf, Castelino, and Francis (1987) derive hedging parameters for mispriced options.

\section{Methodology}

The basic approach of this paper is to estimate an underlying asset price process as GARCH-t components with leverage, and then estimate hedging parameters for options on this asset using Monte-Carlo simulation. Initially, it is useful to discuss the specification of the GARCH model. The GARCH model reflects many of the observed dynamics of asset returns volatility including short and long run mean reversion and asymmetric effects of underlying price movements on volatility. It is specified as follows: 
(1) $\ln \left(r_{t}\right)=e_{t} ; e_{t}=z_{t} \sigma_{t}$

(2) $\sigma_{t}^{2}=q_{t}+\alpha\left(e_{t-1}^{2}-q_{t-1}\right)+\delta\left(D_{t-1} e_{t-1}^{2}-.5 q_{t-1}\right)+\beta\left(\sigma_{t-1}^{2}-q_{t-1}\right)$

$D_{t-1}=1$ if $e_{t-1}<1$, 0 otherwise

(3) $q_{t}=\omega+\rho q_{t-1}+\phi\left(e_{t-1}^{2}-\sigma_{t-1}^{2}\right)$

(4) $z_{1} \sim$ standardized Student 's $-t(v)$

In this model, log prices follow a random walk with time-varying volatility, and volatility is related to its own lags as well as lag returns. At time $t, z$ is the random shock, $\sigma$ is the conditional standard deviation, $\mathrm{q}$ is the conditional volatility trend, and $\mathrm{r}$ is the underlying return.

Of the parameters, $\alpha$ reflects the effect of a shock on the temporary component of volatility, $\delta$ captures the asymmetric effect of "bad news" on volatility, $\beta$ reflects the influence of the prior day's volatility forecast, $\rho$ measures the persistence of the long term component, and $\varphi$ represents the effect of a shock on the permanent component. Shocks are selected from a standardized Student's-t distribution with $v$ degrees of freedom where $v$ is estimated to emulate the observed leptokurtosis in many financial returns time-series.

Engle and Lee (1993) show that the GARCH components model is equivalent to a $\operatorname{GARCH}(2,2)$ model. In fact, with tho and phi equal to zero, the components model simplifies to a $\operatorname{GARCH}(1,1)$ model. We take advantage of this simplification in our estimation process, when the components parameters are statistically insignificant.

Several simplifying assumptions are made for option valuation purposes. We suppose that conditions necessary to invoke risk-neutral valuation are satisfied. Sufficient conditions are discussed in Section II. Options are all assumed to be European. We also assume that futures prices are unaffected marking to market, uncertain delivery dates, 
and the quality option. Finally, interest rates are assumed to be constant, while dividends are assumed to be known.

We then apply risk-neutral valuation in a straightforward way for the different types of options. Merton (1973) generalizes BS to options on assets with a known dividend yield. This methodology is used to price S\&P500 index options. Black (1976) shows that options on futures can be valued as standard options with the dividend yield set equal to the risk-free rate. This method is applied for options on oil and bond futures indices. Garman and Kohlhagan (1983) and Grabbe (1983) show that foreign exchange options can be valued as standard options with the dividend yield replaced by the foreign riskfree rate. We utilize this result as well.

We estimate hedging parameters by simulating the effect of an underlying return shock on the option price. The option price is evaluated using risk-neutral valuation as given by equation (5). That is, the option price is the present value of the expected payoff of the option, where the expectation is taken with respect to the probability distribution of terminal prices given by the GARCH components process, with drift equal to the riskfree rate. The distribution of the terminal underlying price is estimated using MonteCarlo simulation of the asset price path under the GARCH volatility process as given by equation (6). 50,000 terminal prices are generated, and the antithetic variate technique is used to improve the efficiency of the option price estimate.

(5) $C_{1}\left(S_{1}, \sigma_{1}^{2}, q_{1}, T\right) \stackrel{R N V R}{=} e^{-r T} E\left\{\max \left[0, S_{T}-K\right] S_{1}, \sigma_{1}^{2}, q_{1}, T\right\}$

$$
\stackrel{C L T}{\cong} \hat{C}_{1}\left(S_{1}, \sigma_{1}^{2}, q_{1}, T\right)=\frac{1}{N} e^{-r t} \sum_{j=1}^{N}\left\{\max \left[0, S_{T, j}-K\right] \mid S_{1}, \sigma_{1}^{2}, q_{1}, T\right\}
$$

(6) $S_{t, j}=\exp ^{r-\frac{\sigma_{t, j}}{2}+e_{t, j} \sigma_{t, j}} S_{t-1, j} ; \sigma_{t, j}^{2}, e_{t, j}$ are generated by $\operatorname{GARCH}(\alpha, \beta, \delta, \rho, \phi, v)$ $e_{t, j} \sim$ standardized Student' $\mathrm{s}-\mathrm{t}(\mathrm{v}), \mathrm{j}=1 \ldots 50,000, \mathrm{t}=1 \ldots \mathrm{T}$

The initial volatility forecasts, $\sigma^{2} 1$ and $q_{1}$ are set equal to the unconditional variance, as a default case. The implication is that volatility is currently at its long run level. 
Changing the initial variance will affect the hedging parameters, since average volatility will depend on the maturity of the option.

The hedging problem in discrete time involves neutralizing the option portfolio to a change in today's underlying price. The first derivative of today's option price with respect to today's underlying price does not depend on yesterday's price in a BlackScholes world, since returns carry no information about volatility. However, in a discrete time hedging problem with time-varying volatility, the price yesterday does have useful information.

In equations (7) and (8), the finite difference estimate of the first and second derivatives of option prices at time 1 are given, and both $S_{0}$ and $S_{1}$ are listed as arguments.

(7) $\Delta_{G A R C H}=\frac{\partial C_{1}\left(S_{0}, S_{1}, \sigma_{1}^{2}, q_{1}, T\right)}{\partial S_{1}} \cong \frac{\hat{C}_{1}\left(S_{0}, S_{0}+\varepsilon, \sigma_{1}^{2}, q_{1}, T\right)-\hat{C}_{1}\left(S_{0}, S_{0}-\varepsilon, \sigma_{1}^{2}, q_{1}, T\right)}{2 \varepsilon}$

(8) $\Gamma_{0, G A R C H}=\frac{\partial^{2} C_{1}\left(S_{0}, S_{1}, \sigma_{1}^{2}, q_{1}, T\right)}{\partial S_{1}^{2}} \cong \frac{\hat{C}_{1}\left(S_{0}, S_{0}+\varepsilon, \sigma_{1}^{2}, q_{1}, T\right)-2 \hat{C}_{1}\left(S_{0}, S_{0}-\varepsilon, \sigma_{1}^{2}, q_{1}, T\right)+\hat{C}_{1}\left(S_{0}, S_{0}-\varepsilon, \sigma_{1}^{2}, q_{1}, T\right)}{\varepsilon^{2}}$ $\varepsilon=1 \sigma_{1}^{*} S_{0}$

Equations (7) and (8) are estimated using an initial index price of 10000 with $\varepsilon$ set to a one-tenth standard deviation price shock. The polynomial function in (9) is fitted to the simulated hedge ratios using least squares, with one function for each moneyness. The final hedge ratios are given by the fitted values from the estimated function in equation (10).

(9) $\log \left(\Gamma\left(S_{0}, T, K\right)\right)=\hat{a}+\hat{b} T+\hat{c} T^{\frac{1}{2}}+\hat{d} T^{-\frac{1}{2}}+\hat{e} T^{-1}+\hat{f} T^{-2}+\hat{g} T^{-3}+\varepsilon_{T, K}$

(10) $\hat{\Gamma}\left(S_{0}, T, K\right)=\exp \left(\hat{a}+\hat{b} T+\hat{c} T^{\frac{1}{2}}+\hat{d} T^{-\frac{1}{2}}+\hat{e} T^{-1}+\hat{f} T^{-2}+\hat{g} T^{-3}\right)$ 
As mentioned in the introduction, under GARCH volatility, the response of the option price to volatility changes is incorporated directly in GARCH delta and gamma. Thus, we do not estimate a separate vega parameter.

\section{Estimation of GARCH models}

GARCH models are estimated for four underlying assets: the S\&P500 index, a Treasury bond futures index, a weighted exchange rate index, and a crude oil futures index. For each underlying asset, we have a daily returns time-series of 2114 observations over the period from June 1983 through mid-May 1994 from the Datastream database. The data was provided by Salomon Brothers. The oil and bond futures index prices are taken from contracts rolled on the first of the month. The weighted foreign exchange index prices are from an index developed by the Bank of England. Table 1 lists the sample statistics for the index $\log$ returns.

As expected, all of the series exhibit substantial departures from normality. In particular, normality is rejected for all series at the .001 level using the Kolmogorov D test. All the series exhibit excess kurtosis, while the oil futures and S\&P500 index exhibit substantial negative skewness. All mean log returns are within 4 basis points of zero, while there are large differences in volatility. The oil futures series is the most volatile with a daily standard deviation of $2.8 \%$, more than 5 times greater than the foreign exchange index standard deviation of $.5 \%$.

There is evidence for autocorrelation in the log returns of the S\&P500, the oil futures index, and marginal evidence in the bond futures index. However, using the standardized log returns, no series exhibits autocorrelation. All of the series show strong autocorrelation in their squared returns, which is an indication of GARCH-type heteroskedasticity. 
We use maximum likelihood estimation to estimate one GARCH model for each logreturn series, where the log-returns are assumed to be Student's-t with $v$ degrees of freedom. Table 2 reports the parameter estimates for each model along with Ljung-Box statistics. In some models, insignificant variables are excluded in the final estimation. When components parameters are not significant, the model is estimated as a $\operatorname{GARCH}(1,1)$ and the parameters should be interpreted accordingly.

GARCH-t components models provide the best fit for the S\&P500 and oil futures index volatility, while a $\operatorname{GARCH}(1,1)-\mathrm{t}$ model is best for the bond futures and exchange rate index volatility. The leverage effect is marginally significant in the bond futures model using robust t-statistics. It is insignificant in the S\&P500 model. However, Engle and Lee (1993) find the S\&P500 leverage effect to be significant in a model estimated over a longer time period, so we include it in our model. There is strong evidence that the underlying shocks are non-normal, since $1 / v$ is significantly greater than zero for all models.

\section{Estimation of hedge parameters}

Using the Monte-Carlo techniques described in section III and IV, we estimate GARCH delta and gamma for options on the Standard and Poor's 500 index, a bond futures index, a weighted foreign exchange rate index, and an oil futures index. Hedge parameters are estimated for moneynesses ranging from .8 to 1.2 , and for maturities of 1 to 250 days. GARCH deltas are not reported, but are discussed below.

There are several notable characteristics of GARCH deltas. First, GARCH deltas are very close to BS deltas for at-the-money options, except when there is strong leverage effect. Second, out-of-the-money options have higher GARCH deltas and in-the-money options have lower GARCH deltas than BS. However, all GARCH deltas are close to BS deltas, with the maximum difference being .12 for the oil futures options. For foreign 
exchange, bond futures, and S\&P500 index options, the maximum differences are .02, .07 , and .03 respectively.

GARCH gammas are reported for options on each index in Table 3. The formulas in each table can be used for either calls or puts, for any risk-free or dividend rate, and various combinations of index levels and strike prices. Each table corresponds to an underlying index, and each column corresponds to an option's moneyness ( $\left(S^{\prime} / K^{\prime}\right)$. The column gives the coefficients for the hedge parameter equation, so that the hedge parameters can be calculated using equation (10).

There are substantial differences between BS and GARCH gammas. These result in even larger differences in gamma hedge ratios. Figures 1 and 2 display gammas for out-ofthe money options on the S\&P500 derived from BS and GARCH. GARCH gammas are higher than BS gammas, because they reflect the dual impact of the second order effects of an underlying price shock. First, as in Black-Scholes, the underlying price shock has a positive second-order effect on the options price; and, second, the underlying price shock increases future volatility which further increases the option price. GARCH gammas also decay more slowly, since the decline of convexity as maturity increases is partly offset by the increase in the sensitivity of the option price to a volatility shock as maturity increases. For substantially away-from-the-money options, both BS and GARCH gammas approach zero.

Table 4 reports the BS and GARCH gamma hedge ratios for hedging a near-the-money long term option on the S\&P500 index with a short term option having the same strike price, assuming no dividends and a risk-free rate of zero. For near-the-money hedges, GARCH gamma hedge ratios are significantly higher than BS hedge ratios due to the slower decay of GARCH gamma. For instance, under BS assumptions, gamma hedging one 60 day at-the-money option contract requires .5820 day contracts. In contrast, 
using GARCH gammas, 6920 day contracts are needed. In contrast, for away-fromthe-money options, GARCH hedge ratios are lower than BS hedge ratios.

As with Black-Scholes gammas, GARCH gammas are sensitive to the level of volatility. Figure 3 compares GARCH gamma for S\&P500 index options with different maturities and three different levels for the initial variance. The initial variance is set equal to the unconditional variance which indicates a flat expected term structure of volatility, fifty percent below the unconditional variance which indicates an upward sloping expected term structure of volatility, and fifty percent above the unconditional variance which indicates a downward sloping expected term structure of volatility. Figure 3 indicates that changing the term structure shapes affects the gammas less than moneyness, but it does have an important impact. This indicates that new GARCH gammas should be estimated at the current volatility level, if volatility is away from its long-term mean.

\section{Conclusion}

This paper develops a methodology for estimating option hedge parameters when the underlying asset exhibits stochastic volatility. We find substantial evidence for GARCHtype stochastic volatility in four index returns time-series and estimate GARCH delta and gamma using Monte-Carlo simulation. GARCH deltas are similar to Black-Scholes deltas, while GARCH gammas and gamma hedge ratios are quite different. This suggests that there is potential for more effective option gamma hedging by accounting for the relationship between price changes and volatility. In particular, it is possible that incorporating GARCH volatility into option models will enhance hedge performance. 


\section{Bibliography}

Amin, K. I. and V. K. Ng. "Option Valuation with Systematic Stochastic Volatility," Journal of Finance, 48 (July 1993), pp. 881-910.

Ball, C. and A. Roma. "Stochastic Volatility Option Pricing," Journal of Financial and Quantitative Analysis, 29 (December 1994), pp. 589-607.

Black, F. and M. Scholes. "The Pricing of Options and Corporate Liabilities," Journal of Political Economy, 81 (May 1973), pp. 637-654.

Bollerslev, T. "Generalized Autoregressive Conditional Heteroskedasticity," Journal of Econometrics, 31 (1986), pp. 307-327.

Bollerslev, T. "A Conditionally Heteroskedastic Time Series Model for Speculative Prices and Rates of Return," Review of Economics and Statistics, (1987), pp. 542547.

Boyle, P. P. "Options: A Monte-Carlo Approach," Journal of Financial Economics, 4 (1977), pp. 323-338.

Boyle, P. P. and D. Emanuel. "Discretely Adjusted Option Hedges," Journal of Financial Economics, 8 (September 1980), pp. 259-282.

Brennan, M. "The Pricing of Contingent Claims in Discrete-time Models," Journal of Finance, 34 (1979), pp. 53-68.

Chen, N. F. and H. Johnson. "Hedging Options," Journal of Financial Economics, 14 (1985), pp. 317-321.

Cox, J. C. and S. A. Ross. "The Valuation of Options for Alternative Stochastic Processes," Journal of Financial Economics, 3 (1976), pp. 145-166.

Cox, J. C. and M. Rubinstein. “Options Markets." Englewood Cliffs, New Jersey: Prentice-Hall, 1985.

Duan, J. C. "The GARCH Option Pricing Model," Mathematical Finance, 5 (January 1995), pp. 13-32.

Engle, R. F. "Autoregressive Conditional Heteroscedasticity with Estimates of the Variance of United Kingdom Inflation," Econometrica, 50 (July 1982), pp. 9871007. 
Engle, R. F. and G. Lee. "A Permanent and Transitory Component Model of Stock Return Volatility," University of California - San Diego, UCSD discussion paper, 92-44R, (1993).

Engle, R. F. and J. V. Rosenberg. "Hedging Options in a GARCH Environment: Testing the Term Structure of Stochastic Volatility Models," University of California - San Diego, UCSD discussion paper, 94-25, (1994).

Figlewski, S. "Options Arbitrage in Imperfect Markets," Journal of Finance, 44 (December 1989), pp. 1289-1311.

Figlewski, S. and S. Freund. "The Pricing of Convexity Risk and Time Decay in Options Markets," Journal of Banking and Finance, 18 (1994), pp. 73-91.

Galai, D. "The Components of the Return from Hedging Options Against Stocks," Journal of Business, 56 (January 1983), pp. 45-54.

Garman, M. B. and S. W. Kohlhagan. "Foreign Currency Option Values," Journal of International Money and Finance, 2 (1983), pp. 231-237.

Gilster, J. E., Jr. "The Systematic Risk of Discretely Rebalanced Option Hedges," Journal of Financial and Quantitative Analysis, 25 (1990), pp. 507-516.

Glosten, L. R., R. Jagannathan and D. E. Runkle. "On the Relation Between the Expected Value and the Volatility of the Nominal Excess Return On Stocks," Journal of Finance, 48 (1993), pp. 1779-1801.

Grabbe, J. O. "The Pricing of Call and Put Options on Foreign Exchange," Journal of International Money and Finance, 2 (1983), pp. 239-253.

Heston, S. L. "A Closed-Form Solution for Options with Stochastic Volatility with Applications to Bond and Currency Options," Review of Financial Studies, 6 (1993), pp. 327-343.

Hull, J. and A. White. "Hedging the Risks from Writing Foreign Currency Options," Journal of International Money and Finance, 6 (June 1987a), pp. 131-152.

Hull, J. and A. White. "The Pricing of Options on Assets with Stochastic Volatilities," Journal of Finance, 42 (June 1987b), pp. 281-301.

Jarrow, R. and A. Rudd. "Option Pricing." Homewood, Illinois: Dow Jones-Irwin, 1983.

Johnson, H. and D. Shanno. "Option Pricing When the Variance is Changing," Journal of Financial and Quantitative Analysis, 22 (June 1987), pp. 143-151. 
Lee, W. Y., R. K. S. Rao and J. F. G. Auchmuty. "Option Pricing in a Lognormal Securities Market with Discrete Trading," Journal of Financial Economics, 9 (1981), pp. 75-101.

Merton, R. C. "Theory of Rational Option Pricing," Bell Journal of Economics and Management Science, 4 (1973), pp. 141-183.

Robins, R. P. and B. Schachter. "An Analysis of the Risk in Discretely Rebalanced Option Hedges and Delta-based Techniques," Management Science, 40 (1994), pp. 798-808.

Rubinstein, M. "The Valuation of Uncertain Income Streams and the Pricing of Options," Bell Journal of Economics and Management Science, 7 (1976), pp. 407425.

Scott, L. O. "Option Pricing when the Variance Changes Randomly: Theory, Estimation, and an Application," Journal of Financial and Quantitative Analysis, 22 (December 1987), pp. 419-438.

Stapleton, R. C. and M. G. Subrahmanyam. "The Valuation of Multivariate Contingent Claims in Discrete Time Models," Journal of Finance, 39 (March 1984), pp. 207228.

Stein, E. M. and J. C. Stein. "Stock Price Distributions with Stochastic Volatility - an Analytic Approach," Review of Financial Studies, 4 (1991), pp. 727-752.

Wiggins, J. B. "Option Values under Stochastic Volatility: Theory and Empirical Estimates," Journal of Financial Economics, 19 (1987), pp. 351-372.

Wolf, A., M. Castelino and J. C. Francis. "Hedging Mispriced Options," Journal of Futures Markets, 7 (1987), pp. 147-156. 
Table 1 - Data Summary

Sample Statistics for daily log returns

\begin{tabular}{|c|c|c|c|c|c|c|c|c|}
\hline & $\begin{array}{l}\text { Number of } \\
\text { observations }\end{array}$ & Mean & $\begin{array}{l}\text { Standard } \\
\text { deviation }\end{array}$ & Skewness & Kurtosis & $\begin{array}{l}\text { Kolmogorov } \\
\text { normality test } \\
\text { p-value }\end{array}$ & $\begin{array}{l}\text { Ljung-Box } \\
\text { (15) on log } \\
\text { returns }\end{array}$ & $\begin{array}{l}\text { Ljung-Box } \\
\text { (15) on } \\
\text { squared log } \\
\text { returns }\end{array}$ \\
\hline S\&P500 index & 2114 & 0.0003 & 0.0109 & -6.34 & 145.60 & 0.001 & 36.33 & 80.19 \\
\hline Bond futures index & 2114 & 0.0001 & 0.0070 & -0.07 & 5.25 & 0.001 & 25.78 & 553.88 \\
\hline Exchange rate index & 2114 & -0.0002 & 0.0051 & 0.11 & 4.45 & 0.001 & 23.54 & 108.87 \\
\hline Oil futures index & 2114 & -0.0005 & 0.0283 & -3.30 & 58.14 & 0.001 & 58.32 & 59.50 \\
\hline
\end{tabular}

Sample Statistics for daily standardized log returns (using estimated GARCH model)

\begin{tabular}{|c|c|c|c|c|c|c|c|c|}
\hline & \begin{tabular}{|l|} 
Number of \\
observations
\end{tabular} & $\begin{array}{l}\text { Mean (in } \\
\text { units of } \\
\text { standard } \\
\text { deviations) } \\
\end{array}$ & $\begin{array}{l}\text { Standard } \\
\text { deviation }\end{array}$ & Skewness & Kurtosis & $\begin{array}{l}\text { Kolmogorov } \\
\text { normality test } \\
\text { p-value }\end{array}$ & $\begin{array}{l}\text { Ljung-Box } \\
\text { (15) on } \\
\text { standardized } \\
\text { log returns }\end{array}$ & $\begin{array}{l}\text { Ljung-Box } \\
\text { (15) on } \\
\text { squared } \\
\text { standardized } \\
\text { log returns }\end{array}$ \\
\hline S\&P500 index & 2114 & 0.04 & 1.06 & $\begin{array}{l}-1.12 \\
\end{array}$ & 12.22 & 0.001 & 14.21 & 5.06 \\
\hline Bond futures index & 2114 & 0.01 & 1.00 & -0.19 & 4.46 & 0.001 & 22.75 & 14.96 \\
\hline Exchange rate index & 2114 & -0.03 & 0.99 & 0.06 & 4.35 & 0.001 & 20.99 & 9.32 \\
\hline Oil futures index & 2114 & -0.02 & 1.00 & -0.68 & 8.84 & 0.001 & 9.91 & 12.23 \\
\hline
\end{tabular}


Table 2 - Estimation of GARCH models

Maximum likelihood estimation with $\mathrm{t}$-distribution as the underlying density

2114 observations (June 7, 1986 - May 12, 1994)

S\&P500 index log returns

GARCH-t Components Model

\begin{tabular}{|l|r|r|r|l|r|}
\hline & Coefficient & \multicolumn{1}{l|}{$\begin{array}{l}\text { Standard } \\
\text { error }\end{array}$} & $\begin{array}{l}\text { Robust } \\
\text { t-stand } \\
\text { error }\end{array}$ & $\begin{array}{l}\text { Robust } \\
\text { t-stat }\end{array}$ \\
\hline$\omega$ & $6.00 \mathrm{E}-07$ & $2.00 \mathrm{E}-07$ & 3.00 & $1.13 \mathrm{E}-06$ & 0.53 \\
$\alpha$ & 0.0000 & 0.0221 & 0.00 & 0.0255 & 0.00 \\
$\beta$ & 0.7615 & 0.0615 & 12.39 & 0.2267 & 3.36 \\
$\delta$ & 0.1236 & 0.0347 & 3.56 & 0.1916 & 0.65 \\
$\phi$ & 0.0154 & 0.0059 & 2.62 & 0.0137 & 1.12 \\
$\rho$ & 0.9891 & 0.0031 & 315.57 & 0.0046 & 213.65 \\
$1 / \nu$ & 0.1935 & 0.0177 & 10.95 & &
\end{tabular}

T-bond futures index log returns GARCH $(1,1)$-t model

\begin{tabular}{|l|r|r|r|l|r|}
\hline & Coefficient & \multicolumn{1}{l|}{$\begin{array}{l}\text { Standard } \\
\text { error }\end{array}$} & $\begin{array}{l}\text { Robust } \\
\text { standard } \\
\text { error }\end{array}$ & $\begin{array}{l}\text { Robust } \\
\text { t-stat }\end{array}$ \\
\hline$\omega$ & $3.56 \mathrm{E}-07$ & $1.69 \mathrm{E}-07$ & 2.10 & $2.43 \mathrm{E}-06$ & 0.15 \\
$\alpha$ & 0.0236 & 0.0088 & 2.67 & 0.0095 & 2.49 \\
$\beta$ & 0.9574 & 0.0092 & 103.68 & 0.0092 & 104.50 \\
$\delta$ & 0.0245 & 0.0116 & 2.10 & 0.0127 & 1.92 \\
$1 / v$ & 0.1626 & 0.0240 & 6.77 & \multicolumn{3}{|l}{} \\
\hline
\end{tabular}

Weighted foreign exchange rate index log returns GARCH $(1,1)$-t model

\begin{tabular}{|c|c|c|c|c|c|}
\hline & Coefficient & $\begin{array}{l}\text { Standard } \\
\text { error }\end{array}$ & t-stat & $\begin{array}{l}\text { Robust } \\
\text { standard } \\
\text { error }\end{array}$ & $\begin{array}{l}\text { Robust } \\
\text { t-stat }\end{array}$ \\
\hline$\omega$ & $8.61 \mathrm{E}-07$ & $3.58 \mathrm{E}-07$ & 2.40 & $1.18 \mathrm{E}-06$ & 0.73 \\
\hline$\alpha$ & 0.0495 & 0.0122 & 4.05 & 0.0124 & 3.99 \\
\hline$\beta$ & 0.9190 & 0.0221 & 41.67 & 0.0197 & 46.72 \\
\hline $1 / v$ & 0.1550 & 0.0248 & 6.25 & & \\
\hline
\end{tabular}

Crude oil futures index log returns GARCH-t Components Model

\begin{tabular}{|l|r|r|r|l|r|}
\hline & Coefficient & \multicolumn{1}{l|}{$\begin{array}{l}\text { Standard } \\
\text { error }\end{array}$} & $\begin{array}{l}\text { Robust } \\
\text { standard } \\
\text { t-stat }\end{array}$ & $\begin{array}{l}\text { Robust } \\
\text { t-stat }\end{array}$ \\
\hline$\omega$ & $7.21 \mathrm{E}-06$ & $2.40 \mathrm{E}-06$ & 3.01 & $2.88 \mathrm{E}-05$ & 0.25 \\
$\alpha$ & 0.0787 & 0.0321 & 2.45 & 0.0348 & 2.26 \\
$\beta$ & 0.7149 & 0.1314 & 5.44 & 0.1460 & 4.90 \\
$\phi$ & 0.0985 & 0.0226 & 4.36 & 0.0331 & 2.97 \\
$\rho$ & 0.9953 & 0.0082 & 121.73 & 0.0142 & 70.31 \\
$1 / v$ & 0.2311 & 0.0232 & 9.95 & \multicolumn{3}{|c}{} \\
\hline
\end{tabular}


Table 3 - GARCH gammas

GARCH gamma for options on the S\&P500 index

(estimated for one $\$ 100$ option)

GARCH gamma $=100 /($ current index level $) * \exp \left(-q^{*} T\right) *\left[\exp \left(a+b^{\star} T+c^{*} \operatorname{sqrt}(T)+d / \operatorname{sqrt}(T)+e / T+f / T \wedge 2+g / T \wedge 3\right)\right]$

$T=$ number of trading days until maturity, $r=$ domestic risk-free rate of interest, $q=$ dividend yield

Coefficients are chosen from table below using column $S^{\prime} / K^{\prime}$

$S^{\prime}=\exp \left(-q^{\star} T\right) *$ Current index level

$K^{\prime}=\exp \left(-r^{*} T\right) *$ Strike price

\begin{tabular}{|c|c|c|c|c|c|c|c|c|c|c|c|}
\hline & $S^{\prime} / K^{\prime}$ & & & & & & & & & & \\
\hline Coeff. & 1.20 & 1.15 & 1.10 & 1.05 & 1.02 & 1.00 & 0.98 & 0.95 & 0.90 & 0.85 & 0.80 \\
\hline \begin{tabular}{|l|}
$a$ \\
\end{tabular} & 1.943 & -2.164 & -2.985 & 0.853 & -2.845 & -2.805 & -2.492 & -4.151 & 18.558 & -11.346 & -52.025 \\
\hline$b$ & 0.000 & -0.009 & -0.007 & 0.006 & -0.003 & -0.002 & -0.001 & -0.005 & 0.034 & -0.053 & -0.122 \\
\hline c & -0.119 & 0.188 & 0.159 & -0.250 & 0.047 & 0.033 & 0.003 & 0.135 & -1.423 & 1.440 & 4.344 \\
\hline d & -67.212 & -29.966 & -6.735 & -13.697 & 6.260 & 6.562 & 5.795 & 15.806 & -126.824 & -33.888 & 165.451 \\
\hline$e$ & 115.481 & 31.437 & -21.193 & 8.070 & -11.456 & -7.106 & -11.899 & -61.808 & 185.480 & 96.339 & -237.589 \\
\hline$f$ & -110.942 & -5.342 & 49.192 & -14.229 & 4.989 & 4.989 & 6.215 & 94.303 & -145.829 & -133.325 & 200.393 \\
\hline $\mathrm{g}$ & 51.641 & -3.356 & -27.637 & 10.727 & -0.993 & -1.942 & -1.786 & -53.490 & 60.790 & 71.642 & -89.671 \\
\hline
\end{tabular}

GARCH gamma for options on a T-bond futures index

(estimated for $1 \$ 100$ option)

GARCH gamma $=100 /($ current index level $) * \exp \left(-r^{*} T\right) *\left[\exp \left(a+b * T+c^{*} \operatorname{sqrt}(T)+d / s q r t(T)+e / T+f / T \wedge 2+g / T \wedge 3\right)\right]$

$T=$ number of trading days until maturity, $r=$ domestic risk-free rate of interest

Coefficients are chosen from table below using column $S^{\prime} / K^{\prime}$

$S^{\prime}=$ Current index level - present value of expected coupon payments

$K^{\prime}=$ Strike price

\begin{tabular}{|c|c|c|c|c|c|c|c|c|c|c|c|}
\hline & $S^{\prime} / K^{\prime}$ & & & & & & & & & & \\
\hline Coeff. & 1.20 & 1.15 & 1.10 & 1.05 & 1.02 & 1.00 & 0.98 & 0.95 & 0.90 & 0.85 & 0.80 \\
\hline a & -46.694 & -16.195 & 26.575 & 1.183 & -1.142 & -1.703 & -1.042 & 11.406 & -2.159 & -57.295 & -50.400 \\
\hline$b$ & -0.130 & -0.071 & 0.036 & 0.002 & -0.001 & -0.003 & -0.001 & 0.024 & -0.043 & -0.142 & -0.079 \\
\hline c & 4.330 & 2.035 & -1.693 & -0.156 & -0.004 & 0.050 & -0.010 & -0.955 & 0.959 & 5.008 & 3.517 \\
\hline d & 125.029 & -20.132 & -193.330 & -13.264 & -0.063 & 1.867 & -0.276 & -66.033 & -84.679 & 180.888 & 182.390 \\
\hline e & -155.280 & 83.541 & 330.044 & -31.732 & -9.133 & 1.100 & -9.320 & 53.109 & 186.247 & -253.696 & -290.170 \\
\hline$f$ & 102.560 & -131.416 & -326.586 & 86.591 & 2.046 & -2.739 & 2.113 & 15.277 & -227.343 & 206.868 & 278.062 \\
\hline$g$ & -39.018 & 73.052 & 155.761 & -51.837 & 2.177 & 1.604 & 2.461 & -22.049 & 117.836 & -90.846 & -132.555 \\
\hline
\end{tabular}


Table 3 - GARCH gammas (continued)

GARCH gamma for options on a weighted foreign exchange rate index

(estimated for one $\$ 100$ option)

GARCH gamma $=100 /\left(\right.$ current index level) * $\exp \left(-r f^{\star} T\right) *\left[\exp \left(a+b^{\star} T+c^{\star} \operatorname{sqrt}(T)+d / \operatorname{sqrt}(T)+e / T+f / T \wedge 2+g / T \wedge 3\right)\right]$

$T=$ number of trading days until maturity, $r=$ foreign risk-free rate of interest, $r d=$ domestic risk-free rate of interest

Coefficients are chosen from table below using column $S^{\prime} / K^{\prime}$

$S^{\prime}=\exp (-r f * T) *$ Current index level

$K^{\prime}=\exp \left(-r d^{*} T\right) *$ Strike price

\begin{tabular}{|c|c|c|c|c|c|c|c|c|c|c|c|}
\hline & $\mathrm{S}^{\prime} / \mathrm{K}^{\prime}$ & & & & & & & & & & \\
\hline Coeff. & 1.20 & 1.15 & 1.10 & 1.05 & 1.02 & 1.00 & 0.98 & 0.95 & 0.90 & 0.85 & 0.80 \\
\hline \begin{tabular}{|l|}
$a$ \\
\end{tabular} & -46.386 & -12.319 & 28.112 & 3.388 & -0.169 & 0.155 & -0.171 & 3.935 & 18.128 & -26.078 & -37.319 \\
\hline b & -0.108 & -0.049 & 0.050 & 0.009 & 0.002 & 0.003 & 0.002 & 0.010 & 0.025 & -0.074 & -0.061 \\
\hline c & 3.826 & 1.402 & -2.062 & -0.409 & -0.145 & -0.175 & -0.146 & -0.444 & -1.198 & 2.406 & 2.548 \\
\hline d & 140.928 & -26.898 & -188.507 & -23.898 & -3.052 & -4.531 & -2.704 & -26.888 & -147.028 & 38.563 & 118.743 \\
\hline e & -198.426 & 83.759 & 308.590 & 1.999 & -2.857 & 8.837 & -4.474 & 4.012 & 247.956 & -22.996 & -182.620 \\
\hline$f$ & 162.141 & -120.971 & -290.759 & 20.997 & -1.343 & -8.010 & 2.794 & 25.086 & -240.657 & -18.158 & 168.180 \\
\hline g & -71.189 & 65.885 & 135.378 & -11.294 & 2.067 & 3.720 & -0.822 & -14.920 & 113.576 & 17.139 & -78.694 \\
\hline
\end{tabular}

GARCH gamma for options on a crude oil futures index

(estimated for one $\$ 100$ option)

GARCH gamma $=100 /\left(\right.$ current index level) $* \exp \left(-r^{\star} T\right) *\left[\exp \left(a+b^{\star} T+c^{*} \operatorname{sqrt}(T)+d / s q r t(T)+e / T+f / T \wedge 2+g / T \wedge 3\right)\right]$

$\mathrm{T}=$ number of trading days until maturity, $r=$ domestic risk-free rate of interest

Coefficients are chosen from table below using column $S^{\prime} / K^{\prime}$

$S^{\prime}=$ Current index level

$K^{\prime}=$ Strike price

\begin{tabular}{|c|c|c|c|c|c|c|c|c|c|c|c|}
\hline & $S^{\prime} / K^{\prime}$ & & & & & & & & & & \\
\hline Coeff. & 1.20 & 1.15 & 1.10 & 1.05 & 1.02 & 1.00 & 0.98 & 0.95 & 0.90 & 0.85 & 0.80 \\
\hline$a$ & 1.181 & -0.238 & -0.235 & -0.537 & -0.273 & -0.415 & -0.534 & -0.918 & -0.705 & 0.019 & 0.724 \\
\hline$b$ & 0.009 & 0.005 & 0.005 & 0.004 & 0.004 & 0.004 & 0.004 & 0.003 & 0.003 & 0.005 & 0.006 \\
\hline c & -0.330 & -0.212 & -0.201 & -0.168 & -0.185 & -0.174 & -0.160 & -0.127 & -0.150 & -0.207 & -0.255 \\
\hline$d$ & -18.977 & -10.974 & -11.141 & -9.797 & -11.156 & -10.337 & -9.915 & -7.900 & -8.431 & -12.430 & -17.323 \\
\hline e & 18.028 & 7.931 & 14.165 & 16.062 & 19.921 & 18.562 & 17.840 & 12.769 & 8.149 & 9.171 & 12.424 \\
\hline$f$ & -16.519 & -6.639 & -16.882 & -17.116 & -20.228 & -18.092 & -18.026 & -13.931 & -9.293 & -8.156 & -6.804 \\
\hline$g$ & 8.497 & 3.316 & 8.972 & 8.215 & 9.794 & 8.689 & 8.647 & 6.654 & 4.714 & 4.469 & 2.711 \\
\hline
\end{tabular}


Table 4 - Comparison of gamma hedge ratios

Hedging longer term contract with shorter term contract (same strike)

Black-Scholes gamma hedge ratios

(risk-free rate $=0$, sigma $=.74 \%$ daily, dividends $=0$ )

\begin{tabular}{|l|r|r|r|r|r|r|r|r|r|r|r|}
\cline { 2 - 10 } \multicolumn{1}{l|}{} & \multicolumn{1}{l}{ Moneyness (S/Ke(-rt)) } & & & & & & \\
Contract & & & & & & & & & & & \\
Maturities & 1.20 & 1.15 & 1.10 & 1.05 & 1.02 & 1.00 & 0.98 & 0.95 & 0.90 & 0.85 & 0.80 \\
\hline $40: 20$ & $>1000$ & 59.16 & 5.39 & 1.29 & 0.78 & 0.71 & 0.77 & 1.22 & 8.49 & 367.50 & $>1000$ \\
$60: 20$ & $>1000$ & 211.27 & 8.65 & 1.29 & 0.65 & 0.58 & 0.65 & 1.19 & 15.88 & $>1000$ & $>1000$ \\
$80: 20$ & $>1000$ & 382.60 & 10.51 & 1.23 & 0.57 & 0.50 & 0.57 & 1.13 & 20.81 & $>1000$ & $>1000$ \\
$100: 20$ & $>1000$ & 532.71 & 11.51 & 1.17 & 0.52 & 0.45 & 0.52 & 1.07 & 23.87 & $>1000$ & $>1000$ \\
$120: 20$ & $>1000$ & 653.16 & 12.03 & 1.11 & 0.48 & 0.41 & 0.47 & 1.01 & 25.71 & $>1000$ & $>1000$ \\
$140: 20$ & $>1000$ & 746.51 & 12.27 & 1.06 & 0.44 & 0.38 & 0.44 & 0.96 & 26.79 & $>1000$ & $>1000$ \\
$160: 20$ & $>1000$ & 817.80 & 12.33 & 1.01 & 0.42 & 0.35 & 0.41 & 0.91 & 27.38 & $>1000$ & $>1000$ \\
$180: 20$ & $>1000$ & 871.80 & 12.30 & 0.97 & 0.39 & 0.33 & 0.39 & 0.87 & 27.66 & $>1000$ & $>1000$ \\
$200: 20$ & $>1000$ & 912.44 & 12.21 & 0.93 & 0.37 & 0.32 & 0.37 & 0.84 & 27.73 & $>1000$ & $>1000$ \\
$220: 20$ & $>1000$ & 942.77 & 12.08 & 0.90 & 0.36 & 0.30 & 0.35 & 0.81 & 27.66 & $>1000$ & $>1000$ \\
$240: 20$ & $>1000$ & 965.13 & 11.92 & 0.87 & 0.34 & 0.29 & 0.34 & 0.78 & 27.49 & $>1000$ & $>1000$ \\
\hline
\end{tabular}

GARCH simulated gamma hedge ratios estimated for the S\&P500 index

(risk-free rate $=0, h 1=q 1=.74 \%$ daily, dividends $=0$ )

\begin{tabular}{|c|c|c|c|c|c|c|c|c|c|c|c|}
\hline \multirow[b]{2}{*}{$\begin{array}{l}\text { Contract } \\
\text { Maturities }\end{array}$} & \multicolumn{11}{|c|}{ Moneyness (S/Ke(-rt)) } \\
\hline & 1.20 & 1.15 & 1.10 & 1.05 & 1.02 & 1.00 & 0.98 & 0.95 & 0.90 & 0.85 & 0.80 \\
\hline $40: 20$ & 4.47 & 3.87 & 2.80 & 1.45 & 0.90 & 0.79 & 0.90 & 1.63 & 7.24 & 5.26 & 1.41 \\
\hline $60: 20$ & 10.52 & 7.75 & 4.31 & 1.59 & 0.84 & 0.69 & 0.82 & 1.84 & 16.80 & 17.70 & 3.29 \\
\hline $80: 20$ & 18.27 & 11.94 & 5.49 & 1.62 & 0.79 & 0.64 & 0.76 & 1.91 & 25.39 & 42.08 & 7.85 \\
\hline $100: 20$ & 26.86 & 15.98 & 6.37 & 1.61 & 0.75 & 0.60 & 0.72 & 1.92 & 31.61 & 78.76 & 17.05 \\
\hline $120: 20$ & 35.64 & 19.65 & 7.02 & 1.58 & 0.71 & 0.57 & 0.68 & 1.91 & 35.71 & 123.92 & 32.80 \\
\hline $140: 20$ & 44.21 & 22.80 & 7.46 & 1.55 & 0.68 & 0.54 & 0.65 & 1.88 & 38.37 & 170.84 & 55.81 \\
\hline $160: 20$ & 52.29 & 25.38 & 7.74 & 1.51 & 0.66 & 0.52 & 0.63 & 1.84 & 40.17 & 212.23 & 84.56 \\
\hline $180: 20$ & 59.74 & 27.38 & 7.89 & 1.48 & 0.63 & 0.50 & 0.60 & 1.80 & 41.56 & 242.26 & 115.11 \\
\hline $200: 20$ & 66.50 & 28.83 & 7.92 & 1.45 & 0.61 & 0.48 & 0.58 & 1.75 & 42.83 & 257.73 & 142.08 \\
\hline $220: 20$ & 72.55 & 29.78 & 7.87 & 1.43 & 0.58 & 0.46 & 0.56 & 1.70 & 44.20 & 258.32 & 160.38 \\
\hline $240: 20$ & 77.89 & 30.26 & 7.74 & 1.41 & 0.56 & 0.45 & 0.55 & 1.65 & 45.80 & 245.95 & 166.84 \\
\hline
\end{tabular}


Figure 1 - Black-Scholes gamma

Out-of-the-money options

(risk-free rate $=0$, dividends $=0$, sigma $=.74 \%$ daily)

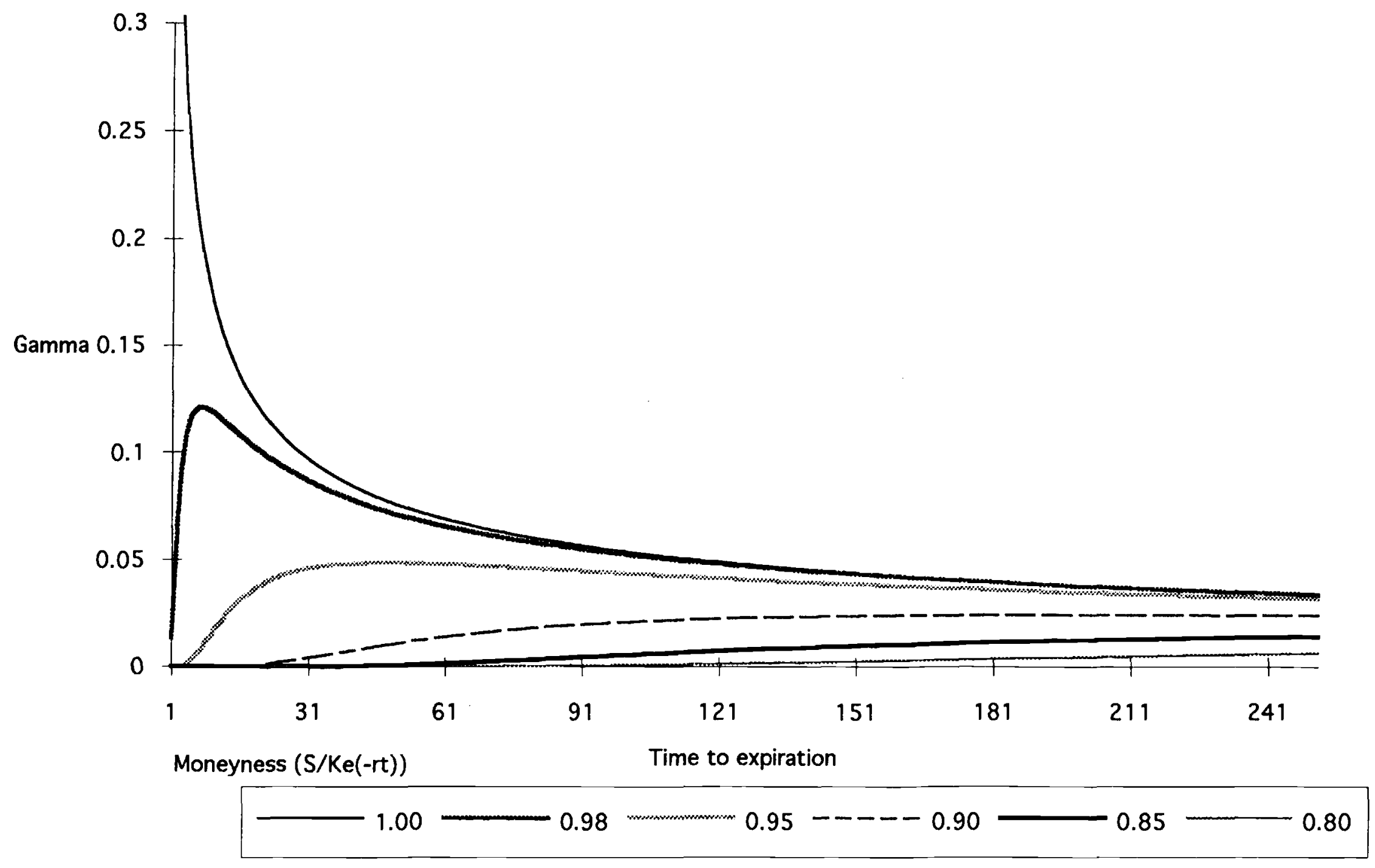


Figure 2 - GARCH gamma (smoothed), out-of-the-money options Estimated for options on the S\&P500 index

(risk-free rate $=0$, dividends $=0$, sigma $1=\operatorname{Sqrt}(q 1)=.74 \%$ daily)

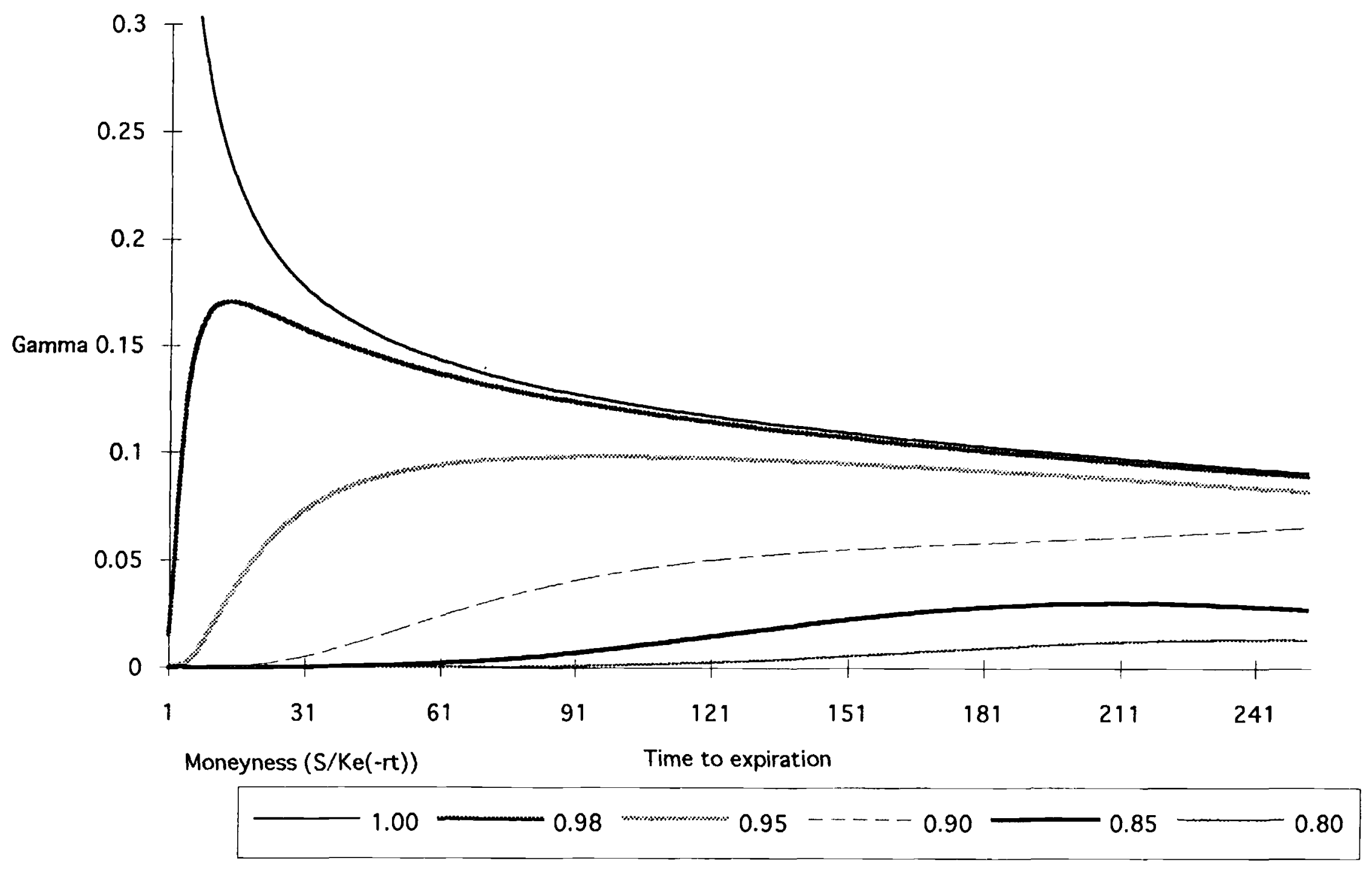


Figure 3 - GARCH gamma

Estimated for near-the-money options on the S\&P500 index

At initial volatility $=.52 \%$ (Upward sloping TS),

$.74 \%$ (Flat TS), .91\% (Downward sloping TS)

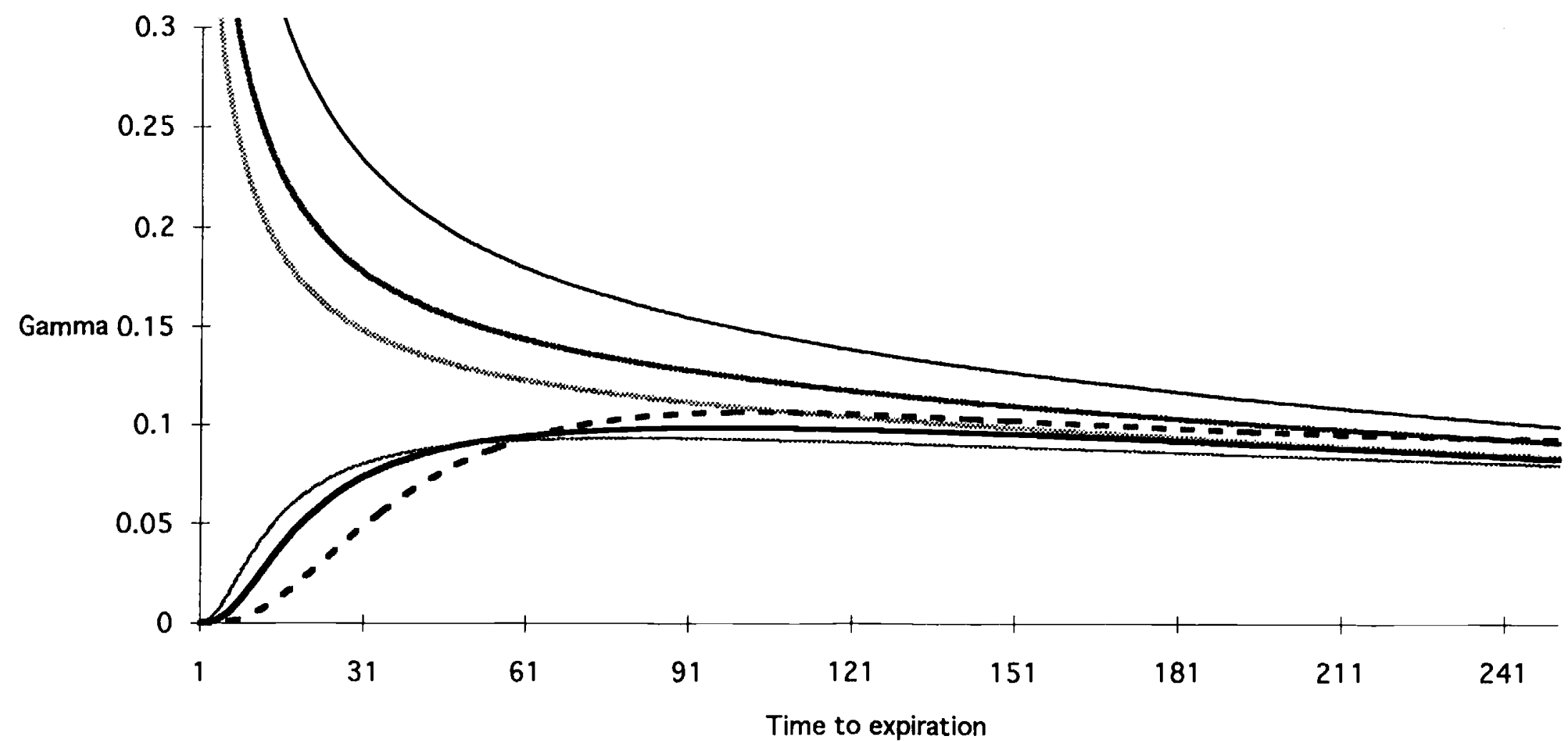

\begin{tabular}{|c|c|c|}
\hline $\begin{array}{l}S / K=1.00 \text { (Upward } \\
\text { sloping TS) }\end{array}$ & $\mathrm{S} / \mathrm{K}=1.00$ (Flat TS) & $\begin{array}{l}S / K=1.00 \\
\text { (Downward sloping } \\
\text { TS) }\end{array}$ \\
\hline $\begin{array}{c}----\quad \text { S/K-.95 (Upward } \\
\text { sloping TS) }\end{array}$ & $\mathrm{S} / \mathrm{K}=.95$ (Flat TS) & $\begin{array}{l}S / K=.95 \text { (Downward } \\
\text { sloping TS) }\end{array}$ \\
\hline
\end{tabular}

